\title{
Clinico-Radiological Profile of Patients Admitted With Osteoarthrosis of the Knee in Rural Population
}

\author{
Dr. Charudatta V. Shinde, M.S. MCh ( Orthopaedics ) \\ Additional Civil Surgeon District Dhule Maharashtra. India 424001.
}

\begin{abstract}
AIM AND OBJECTIVES: 1. To study clinicoradiological findings in cases of Medial compartment osteoarthrosis of knee joint. 2. To study Biomechanics of knee joint with special reference to knee in osteoarthrosis. 3. To compare the results with other available series

METHODOLOGY: The patients for the present study of A clinical study of role of Medial opened wedge tibial osteotomy in medial compartment osteoarthrosis of knee were selected from cases of osteoarthrosis of knees attending Orthopaedic O.P.O. of Pravara Rural Hospital, Loni India. Clinical and radiological assesement and grading was done.

Results: Osteoarthrosis of knee joint we found to be common in patients between 45 to 65 years of age [82.60\%], in over weighted patients it was earlier and was more severe. Majority Le. $69.57 \%$ patients were females and $31.43 \%$ were males. Most of the patients had right sided involvement [65.22\%]. In Medial compartment osteoarthrosis varus deformity of varying degree was commonly found. Most of the patients had complaints about osteoarthrosis of more than 1 year duration [69.57\%]. Many of the patients of present study had patella femoral arthritis [43.48\%] and could be responsible, at least to some extent, for the persistent or recurrence of pain following osteotomy. In the present study $52.81 \%$ patients had 5 to 8degree varus angulation and one patient had 2degree of valgus angulation pre-operatively. Results of the present series are comparable to other published series of high tibial osteotomies.
\end{abstract}

Key words: Osteoarthrosis, knee joint

\section{Introduction}

Osteoarthrosis or osteoarthritis is not a disease by itself. It is the effect of degenerative processes. Osteoarthrosis is a well-known entity even before the understanding of biomechanics of joint and its effect on articular cartilage. This disease leaves a long lasting impact on the personality due to the loss of confidence, depression and social isolation. Hence the need for the treatment of osteoarthrosis has become essential. Thus in such a fast moving world it has become absolute mandatory to offer some solution to the problems produced by osteoarthrosis.

In this era of increasing life expectancy and change in the lifestyle, osteoarthrosis of weight bearing joints, particularly the knee joint has become the most common Orthopaedic problem of enormous magnitude. Osteoarthrosis is the most common disorder in elderly population. The survey had shown that osteoarthrosis can involve any population irrespective of geographical location or climate [1]. After the age of 60 years large population suffer from osteoarthrosis of the knee joint [2]. This is one of the major causes for morbidity at that age, which increases with age. The symptoms like pain, joint stiffness, instability, deformity and loss of function may lead to functional disability even to the extent of affecting their bread wining capacity.

Pathological studies have shown that the knee joint is the most commonly affected joint by osteoarthrosis as compared to other joint in the body. [HEINE, 1926] [3] This is the result of aging. Cytokines and growth factors are thought to play a role in the patho-physiology of the disorders. Interleukin-1 and tumor necrosis factor-b may function to activate enzymes involved in proteolytic digestion of cartilage. Growth factors such as tissue growth factor-b and insulin growth factor-1 may role in the body's attempts to repair cartilage through cartilage synthesis. When catabolism exceeds cartilage synthesis, osteoarthrosis develops. Thus there is break down of articular cartilage, eburnation of the bone and even the disorganization of the joint compartment.

It is now well proved fact that out of total body weight, $60 \%$ of weight is transmitted by muscles and $40 \%$ by bones [4]. At that age the physical activities of the people reduce considerably, there by leading to muscle wasting particularly Quadriceps \& Hamstring muscles. This invites bone to shear more than $40 \%$ of body weight and therefore pain in joint and subsequent structural and biomedical problems.

This study has been carried out in rural population where patient are from a low socioeconomic status as they are many a times the bread earners of the family. Medial opened wedge tibial osteotomy fixed with standard ring fixator will be very useful for them as being of low cost and giving them immediate pain free mobilization, so that they can carry out their routine activities freely and as early as possible. The procedure is simple, safe and effective method. It is a small operation with negligible blood loss and no blood transfusion is 
required. No anesthesia is necessary to remove the apparatus. The fact that all of the patients requiring bilateral osteotomy return for the operation to be performed on the opposite side speaks for itself.

\section{Aims And Objectives}

To study clinicoradiological findings in cases of Medial compartment osteoarthrosis of knee joint.

To study Biomechanics of knee joint with special reference to knee in osteoarthrosis.

To compare the results with other available series.

\section{Clinical Material And Method}

The patients for the present study of A clinical study of role of Medial opened wedge tibial osteotomy in medial compartment osteoarthrosis of knee were selected from cases of osteoarthrosis of knees attending Orthopaedic O.P.O. of Pravara Rural Hospital, Loni India.

\section{GRADING OF RESULTS}

EXCELLENT - $\quad$ 1. Completely pain free

2. Improved free range of flexion as compared

to its pre-operative status. OR

2. Free range of flexion more than $90^{\circ}$

GOOD $\quad$ - $\quad$ 1. Grade 1 pain (mild pain)

2. Free range of flexion same as pre-operative. OR

2. Free range of flexion more than $90^{\circ}$

FAIR $\quad$ - $\quad$ 1. Grade" pain (moderate pain)

2. Pain free or mild pain without flexion possible Up to $90^{\circ}$.

POOR $\quad$ - $\quad$ 1. Grade III pain (severe pain)

2. Pain with flexion less than $90^{\circ}$.

\section{RADIOLOGICAL ASSESSMENT}

The radiological assessment was also carried out to study the relation between the post-operative Tibio - femoral angle and the results using the criteria employed by Coventry (1965) [5].

$5^{\circ}-13^{\circ}$ valgus alignment is ideal and has satisfactory results.

Grade I - The knee that maintained $5^{\circ}-13^{\circ}$ of valgus as shown by Coventry (1965) [5] Insall (1974) [6] Maquet (1976)[7].

Grade II - The knee in which the alignment was not ideal with less than $5^{\circ}$ or more than $14^{\circ}$ of valgus alignment.

\section{Observation Tables}

In the present series, 23 patients were subjected to Medial opened wedge tibial osteotomy stabilized with external ring fixator for medial compartment osteoarthrosis of knee joint.

\section{AGE AND SEX DISTRIBUTION}

In the present series, $56.52 \%$ patients were between 45 to $50 \mathrm{yrs}$ of age. The average age was $54 \mathrm{yrs}$.

\section{TABLE -1 AGE AND SEX DISTRIBUTION}

\begin{tabular}{|c|c|c|c|c|}
\hline \multirow[t]{2}{*}{ AGE IN YRS. } & \multicolumn{2}{|c|}{ SEX } & \multirow[t]{2}{*}{ TOTAL } & \multirow[t]{2}{*}{ PERCENTAGE } \\
\hline & MALE & FEMALE & & \\
\hline Below 45 yrs. & 0 & 2 & 2 & $8.70 \%$ \\
\hline $44-55$ yrs. & 3 & 10 & 13 & $56.52 \%$ \\
\hline $55-65$ yrs. & 3 & 3 & 6 & $26.08 \%$ \\
\hline Above 65 yrs. & 1 & 1 & 2 & $8.70 \%$ \\
\hline TOTAL & 7 & 16 & 23 & $100 \%$ \\
\hline Percentage & $30.43 \%$ & 69. & & $100 \%$ \\
\hline
\end{tabular}



i.e. $30.43 \%$

In the present series, out of 23 patients 16 patients were female i.e. $69.57 \%$ and 7 patients were male

\section{WEIGHT OF THE PATIENT}

Majority of patients in this series had weight between 50-70 kg (73.92\%)

\begin{tabular}{lcccc} 
& \multicolumn{3}{c}{ TABLE-II } & WEIGHT OF THE PATIENT \\
WEIGHT OF & \multicolumn{2}{c}{ NO. OF CASES } & PERCENTAGE \\
PATIENT & MALE & FEMALE & TOTAL & \\
\hline Below $50 \mathrm{~kg}$ & 0 & 3 & 3 & $13.04 \%$ \\
$50-70 \mathrm{~kg}$ & 5 & 12 & 17 & $73.92 \%$ \\
Above 70 kg & 2 & 1 & 3 & $13.04 \%$ \\
\hline TOTAL & 7 & 16 & 23 & $100 \%$ \\
\hline
\end{tabular}

SIDE OF INVOLVEMENT

Majority of patients in this present study had Right sided involvement (65.22\%).

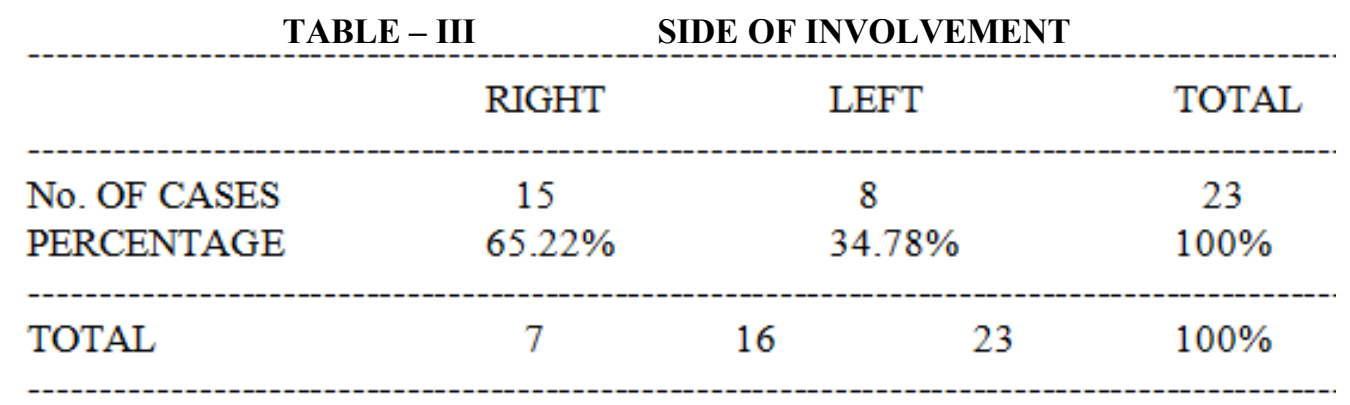

\section{PREOPERATIVE DURATION OF OSTEOARTHROSIS OF KNEE} duration.

Most of the patients in this series had complaints of osteoarthrosis (mostly pain) of more than $1 \mathrm{yr}$. of

TABLE - IV PREOPERATIVE DURATION OF OSTEOARTHROSIS OF KNEE

\begin{tabular}{lll}
\hline DURATION IN YRS. & NO. OF PATIENTS PERCENTAGE \\
\hline Below 1 yrs. & 7 & $30.43 \%$ \\
Above 1 yrs & 16 & $69.57 \%$ \\
\hline TOTAL & 23 & $100 \%$ \\
\hline
\end{tabular}

ASSOCIATION WITH PATELLO-FEMORAL ARTHRITIS

$43.48 \%$ patients in this series were associated with mild to moderate patellofemoral arthritis.

TABLE V - ASSOCIATION WITH PA TELLO-FEMORAL ARTHRITIS

$\begin{array}{llll}\begin{array}{l}\text { PATELLO-FEMORAL } \\ \text { ARTHRITIS }\end{array} & \text { NO. OF PATIENTS } & \text { PERCENTAGE } \\ \text { PRESENT } & \begin{array}{l}\text { MILD - } \\ \text { MODERATE - } \\ \text { SEVERE-O }\end{array} & 10 & 43.48 \% \\ \text { ABSENT } & & 13 & 56.52 \% \\ \text { TOTAL } & & 23 & 100 \%\end{array}$




\section{GRADING OF PAIN}

Pre-operatively $60.87 \%$ of knees gave continuous severe pain i.e. grade III in this present study.

TABLE VI - GRADING OF PAIN

$\begin{array}{lcc}\text { GRADE } & \text { NO. OF PATIENTS } & \text { PERCENTAGE } \\ \text { II } & 1 & 4.35 \% \\ \text { II } & 8 & 34.78 \% \\ \text { II } & 14 & 60.87 \% \\ \text { TOTAL } & 23 & 100 \%\end{array}$

\section{DEFORMITY}

In the present study 12 patients i.e. $52.18 \%$ had $50 \_80$ varus angulation pre-operatively. One patient had $2^{\circ}$ valgus angulation showing medial compartment osteoarthrosis radiologically along with significant clinical findings.

TABLE VII - DEFORMITY

\begin{tabular}{lcc} 
VARUS ANGULATION & NO. OF PATIENTS & PERCENT \\
IN DEGREES & 7 & $30.43 \%$ \\
$0-4$ & 12 & $52.18 \%$ \\
$0-8$ & 3 & $13.03 \%$ \\
9 and above & 1 & $4.35 \%$ \\
ONE PATIENT HAD & & \\
VALGUS ANGULATION & 23 & $100 \%$ \\
\hline TOTAL &
\end{tabular}

RANGE OF MOVEMENT PRE-OPERATIVELY

$73.90 \%$ patients had 1260 and more free flexion range of movement pre-operatively.

\begin{tabular}{lcc}
\multicolumn{1}{c}{ TABLE VIII } & - RANGE OF MOVEMENT PRE-OPERATIVELY \\
\hline FLEXION IN & NO. OF PATIENTS & PERCENTAGE \\
DEGREES & 0 & 0 \\
$-85-95$ & 1 & $4.35 \%$ \\
$96-105$ & 1 & $4.35 \%$ \\
$106-115$ & 4 & $17.40 \%$ \\
$116-125$ & 17 & $73.90 \%$ \\
126 and above & 23 & $100 \%$ \\
- TOTAL & -
\end{tabular}

RADIOLOGICAL GRADINGS OF OSTEOARTHROSIS OF KNEE

$60.87 \%$ of patient was grouped in IV i.e. osteoarthritic changes showing joint space $2 \mathrm{~mm}$ or less [given in material and method]. 
TABLE - IX RADIOLOGICAL GRADINGS OF OSTEOARTHROSIS OF KNEE

\begin{tabular}{lll}
\hline GRADE & NO. OF PATIENTS & PERCENTAGE \\
\hline I & 0 & 0 \\
II & 0 & 0 \\
III & 3 & $13.03 \%$ \\
IV & 14 & $60.87 \%$ \\
V & 6 & $26.10 \%$ \\
VI & 0 & 0 \\
TOTAL & 23 & $100 \%$ \\
\hline
\end{tabular}

\section{Summary And Conclusions}

- In the present series, 23 cases of medial compartmental osteoarthrosis of knee joint, who were subjected to Medial open wedge high tibial osteotomy, were studied.

- Osteoarthrosis of knee joint we found to be common in patients between 45 to 65 years of age $[82.60 \%]$, in over weighted patients it was earlier and was more severe.

- Majority Le. $69.57 \%$ patients were females and $31.43 \%$ were males.

- Most of the patients had right sided involvement [65.22\%].

- In Medial compartment osteoarthrosis varus deformity of varying degree was commonly found.

- Most of the patients had complaints about osteoarthrosis of more than 1 year duration [69.57\%].

- Many of the patients of present study had patella femoral arthritis [43.48\%] and could be responsible, at least to some extent, for the persistent or recurrence of pain following osteotomy. In some patients, patello-femoral arthritis became less severe.

- In the present study $52.81 \%$ patients had 5 to 8 degree varus angulation and one patient had 2 degree of valgus angulation pre-operatively.

- Results of the present series are comparable to other published series of high tibial osteotomies.

\section{BIBLIOGRAPHY}

[1]. Lawrance and Sebo; "Geography of osteoarthritis" in the Aetiopathogenesis of Osteoarthritis, edited by Nuki - 1980 [LondonPitman] Page No. 155

[2]. Koshino Tomihisa - Clinical, findings and aetielogy of osteoarthrosis of the knee Asian Medical Journal Vol. -10 No. 11 Nov. 1987

[3]. Jackson J.P., Waugh w. , Green J.P; "High Tibial Osteotomy for Osteoarthritis of the Knee" JBJS 51 -B, P 88,1969

[4]. Gibson P.J., Good fellow J. - stress radiography in degenerative arthritis of the knee JBJS Vol. 68 - B No.4 Aug. 1986. P. $-608$

[5]. Coventry M.B; "Osteotomy of the Tibia for Osteoarthritis of the knee" JBJS 47 - A, P 984-90, 1965

[6]. Insall J.N. , Shoji H, Mayer V; "High Tibial Osteotomy - 5 year evaluation"JBJS 56-A, P 1397,1974

[7]. Maquet P.G.J; CORR - No. 120, P143, 1976 